\title{
A LOGÍSTICA NAS CADEIAS PRODUTIVAS DO AGRONEGÓcIO
}

\section{ARTIGO DE REVISÃO}

SOUZA, André Luiz Alvarenga De ${ }^{1}$

SOUZA, André Luiz Alvarenga De. A logística nas cadeias produtivas do agronegócio. Revista Científica Multidisciplinar Núcleo do Conhecimento. Ano 04, Ed. 08, Vol. 06, pp. 33-54. Agosto de 2019. ISSN: 2448-0959

\section{RESUMO}

O presente trabalho é desenvolvido sob o contexto do agronegócio brasileiro, mais especificamente com enfoque na logística de cadeias produtivas. Através de uma revisão bibliográfica através de fontes secundárias (livros, periódicos, artigos, trabalhos científicos e sites). O tratamento dos mesmos é se utiliza da metodologia qualitativa com algumas análises quantitativas. Sob a motivação da problemática, estão quais são os principais problemas encontrados pelo agronegócio na logística brasileira seus desafios e suas perspectivas aliadas a um artigo de revisão.

Palavras-chave: logística, agronegócio, cadeias produtivas.

\section{INTRODUÇÃO}

As mudanças sociais, econômicas e de mercado nos últimos anos á nível mundial, fizeram com que o agronegócio globalizado se estabelece com caráter incomum de anos atrás. O Brasil diante toda esta globalização deve continuar a produzir alimentos para o povo brasileiro e outras nações do planeta.

\footnotetext{
${ }^{1}$ Doutorando em Educação, Mestre em Administração, Pós Graduado em Educação a Distância, Pós Graduado em Gestão de Pessoas, Graduação em Administração, Serviço Social, Tecnologia em Gestão de Recursos Humanos, Pedagogia.
} 
O que preocupa é que o mundo vai precisar cada vez mais de alimentos e o Brasil tem um grande potencial de atender essa demanda, pois possui grandes recursos naturais os quais o país têm em abundancia, mas devido ao sistema modal de transporte que se utiliza tende a perder grande parte de suas cargas, deixando os alimentos cada vez mais caros.

O Brasil está estabelecido hoje no contexto mundial atual, como celeiro de riquezas em termos de agronegócio. Segundo Rodrigues (2006), o país possui $22 \%$ das terras agricultáveis do mundo, além de elevada tecnologia utilizada no campo, dados estes que fazem do agronegócio brasileiro um setor moderno, eficiente e competitivo no cenário internacional.

"o agronegócio é o maior negócio mundial e brasileiro, no mundo, representa a geração de $U \$ 6,5$ trilhões/ano e, no Brasil, em torno de $R \$ 350$ bilhões, ou $26 \%$ do PIB (29\%, segundo a Confederação Nacional da Agricultura CNA)". (STEFANELO, 2002, p.10)

A maioria dos negócios se dão fora das porteiras, abarcando o suprimento os insumos, o beneficiamento e também o processamento das matérias primas e a distribuição dos produtos. Para (STEFANELO, 2002), estes são pontos que reforçam a importância do agronegócio no Brasil, além de sua grande competitividade e utilização de alta tecnologia, sendo propulsor de desenvolvimento, renda e empregos.

O agronegócio ainda é responsável por grande parte dos recursos humanos utilizados em toda a cadeia, pois temos desde o pessoal que maneja as sementes, planta, colhe, armazena, beneficia, transporta até chegar ao consumidor final. Contudo em regiões não tão desenvolvidas, os setores da agricultura, da agro industrialização e de áreas correspondentes serão importantes para o crescimento da renda e da empregabilidade, (RENAI, 2007, CARLOS LOURENÇO Y BARBOSA DE LIMA).

O Brasil é destaque internacional no que se refere a produção do agronegócio, mas à infraestrutura logística é um de seus maiores obstáculos para o desenvolvimento do agronegócio do brasileiro que está conectado diretamente a malha rodoviária. 
CNT Confederação Nacional do Transporte (2014), o Brasil é o $2^{\circ}$ maior exportador de soja e de milho do mundo. Em 2014, foram 46 milhões de toneladas de soja e 19,5 milhões de toneladas de milho exportadas.

Diante deste cenário ainda existem alguns problemas relacionados ao escoamento de toda a safra, somente as condições do pavimento das rodovias levam a um aumento de $30,5 \%$ no custo operacional. Se fossem eliminados os

gastos adicionais devido a esse gargalo, haveria uma economia anual de $\mathrm{R} \$ 3,8$ bilhões( CNT Confederação Nacional do Transporte,2014).

O agronegócio no Brasil representa para a economia grandes avanços ao país, colocando-o em uma busca de uma estrutura para que se torne eficiente e competitivo frente às oportunidades e ameaças que surgem no setor.

O intuito deste estudo é analisar logística nas cadeias produtivas do agronegócio através de pesquisa bibliográfica, demonstrando através de dados e fontes oficiais o quão importante é o agronegócio e o sistema de transporte rodoviário o Brasil.

\section{REVISÃO LITERÁRIA}

\subsection{LOGÍSTICA: O CONCEITO}

O conceito de logística é reforçado por (Carvalho, 2002, p. 31)

"Logística é a parte do Gerenciamento da Cadeia de Abastecimento que faz planejamento, implementações e conecta-se ao fluxo e armazenamento eficiente e econômico de matérias-primas, produtos semi acabados e produtos acabados, infere-se desde a sua origem até o ponto de consumo final, com o propósito de atender às exigências dos clientes". 
Historicamente a logística nasceu da expertise de militares em abastecer-se com armamentos, munições, medicamento e alimentos, enquanto se deslocavam da sua base para outras posições em linha de batalha.

A Logística está engendrada ao fluxo de suprimentos e informações que se desdobram durante todo o período de transformação da matéria-prima, assim também como o caminho inverso que pode fazer.

Segundo (BALLOU, 2006), a logística empresarial pode ser definida como a gestão integrada das áreas de finanças, marketing e produção dentro da empresa no curso do processo logístico.

Outro ponto importante a ser destacado é o Supply Chain Management focado em uma estratégia de gerenciamento que potencializa as empresas a serem mais dinâmicas e com isso favorecer a competitividade de mercado, devido o uso das tecnologias integrada a cadeia de suprimentos.

(POZO, 2010), Supply Chain Management (SCM) Gestão da Cadeia de Suprimentos, tem representado uma nova e promissora fronteira para as empresas interessadas na obtenção de vantagens competitivas de forma efetiva.

Diante as novas perspectivas do século XXI e com a crescente demanda por produtos, o Supply Chain Management torna-se essencial para todas as empresas não importando o tamanho ou ramo de atividade.

Nos dias atuais a logística está em destaque, pois diante da atual conjuntura Brasileira os gestores empresariais perceberam a grande importância acerca deste tão importante tema. Sua importância para o agronegócio é evidente e vem sendo sentida ao longo do tempo através de cada safra colhida.

\subsection{O AGRONEGÓCIO: CONCEITO}

O termo agribusiness está diretamente associado ao conceito de Agronegócio que surge em 1957, com John Davis e Ray Goldberg, pesquisadores norte americanos. 
o conceito de Agribusiness é "a soma das operações de produção e distribuição de suprimentos agrícolas, das operações de produção nas unidades agrícolas, do armazenamento, processamento e distribuição dos produtos agrícolas e itens produzidos a partir deles". (CRUVINE; MARTIN NETO, 1999)

Em ordenamento ao termo utilizado por John Davis e Ray Goldberg entende-se também que agribusiness é a soma total de todas as operações feitas dentro e fora da fazenda e que envolvem a produção de suprimentos agrícolas e posteriormente o processamento e distribuição de produtos.

No Brasil, o conceito surgiu nos anos de 1980 com a nomenclatura "Complexo Agroindustrial" que posteriormente ao longo dos anos evolui para Agronegócio.

Dentre várias expressões já encontradas sobre agronegócio, o que importa é o conceito que o mesmo agrega que é agronegócio de base empresarial ou familiar envolvendo toda a cadeia produtiva. Dentro do contexto também existem as explicações relacionadas as situações colocadas por John Davis e Ray Goldberg que são "o antes da porteira, o dentro da porteira e o depois da porteira da propriedade".

A explicação destes itens esta relacionado à aquisição de sementes, mudas, fertilizantes, agroquímicos, tratores e implementos que significa (antes da porteira) o outro aspecto está representado pela produção propriamente dita de café, soja, milho, arroz, feijão, pecuária, agro turismo, entre outras, este é o (dentro da porteira) e o beneficiamento, transporte, armazenamento, processamento ou industrialização, comercialização é o (depois da porteira).Tudo isso precisa de sistemas de transporte para serem locomovidos, o que gera também grande impacto em toda a cadeia devido o alto custo relacionado ao transporte dos insumos e produtos no Brasil.

Dentro dos aspectos do agronegócio vale ressaltar as cadeias produtivas por serem consideradas como o conjunto de todos os envolvidos nos processos que envolvem um determinado produto desde a sua concepção até chegar ao consumidor. Cada 
uma das operações compõe um chamado "elo", que forma uma longa cadeia remetendo-se a pensar em encadeamento.

Este enfoque consiste em descrever as operações de produção responsáveis pela transformação da matéria-prima em produto acabado ou semi acabado. Segundo esta lógica, uma cadeia de produção apresenta-se como uma sucessão linear de operações técnicas de produção. (BATALHA, 2001)

Se pensarmos que tudo que é produzido, precisa ser transportado, vendido e comprado pelos consumidores, podemos pensar em relação ao atacado, pois este possui a função de distribuição de alimentos para os centros urbanos, assim como o varejo.

Tal distribuição passa por plataformas centrais que têm tido o papel de concentrar fisicamente o produto e permitir que os varejistas se abasteçam. (ZYLBERSZTAJN, 2005)

Os mercados não funcionam sem custos, ou a custo zero e partindo desta premissa, sabemos que nada é de graça é claro e os produtores rurais precisam de algum modo organizar o escoamento de suas unidades produtivas visando a otimização de tempo e dinheiro.

Diante desta posição de que os mercados têm custos com relação ao seu funcionamento, emerge a possibilidade de ampliar os preceitos neoclássicos de minimização de custos, que consideram apenas os custos mensuráveis dos fatores de produção, incorporando também os custos de transação. (ZYLBERSZTAJN, 2005)

\section{A LOGÍSTICA NAS CADEIAS PRODUTIVAS DO AGRONEGÓCIO}

O agronegócio é um dos maiores negócios da economia brasileira, se não o maior, visto que globalmente se enquadra em um nicho de economia mundial. No ano de 2014 movimentou mais de 1,1 trilhões de reais, sendo 23\% do PIB (BLOG DO PLANALTO DA PRESIDÊNCIA DA REPÚBLICA, 2014). 
O Brasil é considerado mundialmente um dos países com maior potencial agrícola em todo o mundo, para expandir as exportações de produtos relacionados ao agronegócio, em destaque, os ligados aos alimentos e energéticos, como o álcool e bio diesel, porém enfrenta grandes dificuldades internas devido ao sistema modal inserido na política de transportes, (site Portal do Agronegócio, 2004).

No que diz respeito aos transportes, o mercado de frete rodoviário no Brasil, e em particular o de cargas agrícolas, não sofre nenhum tipo de controle pelo governo, isso significa que os preços são formados com base na livre negociação entre a oferta e a procura pelo serviço de transporte. (CAIXETA-FILHO, 1998),

O Brasil ainda se utiliza em grande parte ainda do modelo de transporte rodoviário para escoar a produção o que gera custos em toda a cadeia produtiva.

Afirma que a safra da soja é, sem dúvida, a que mais desestabiliza o mercado de frete, isto é, com a utilização intensa dos serviços de transporte, pois os veículos disponíveis se tornam escassos e os valores de frete se elevam significativamente. (CAIXETA-FILHO, 2001)

Entretanto não podemos aplicar o conceito de agronegócio apenas às grandes corporações, mas a todos os elos dessa corrente que é responsável por levar os produtos do agronegócio às mãos daqueles que o consumirão.

O governo federal anunciou em 2015, investimentos de $\mathrm{R} \$ 198,4$ bilhões nos próximos anos, também frisou a nova fase do Programa de Investimento em Logística (PIL), e que irá privatizar aeroportos, rodovias, ferrovias e portos (site da presidência da república, 2015).

O grande impacto dessas medidas vem de encontro com as políticas agrícolas precárias, escoamento deficiente da safra das unidades produtivas sem falar na falta de apoio estrutural adequado, além da grande queda de rentabilidade de um negócio que pesa muito na balança comercial brasileira afetando diretamente o PIB. 
Sabe-se, então, que quando existe infraestrutura de transportes de qualidade a eficácia do sistema agroindustrial é mais elevada, sendo preponderante no custeio de movimentação de produtos. A logística dos transportes no agronegócio

possui grande proeminência, pois possui grande impacto na determinação dos preços pagos ao produtor.

Outro aspecto de estrangulamento enfrentado pelo setor é a falta de outros modelos de modais de escoamento da produção em detrimento ao rodoviário.

No caso de produtos agrícolas (granéis sólidos), a concentração modal é muito inadequada, sendo o rodoviário responsável por $80 \%$ das cargas, o ferroviário, 8-10\%, e as hidrovias ficam com o restante. (CAIXETA-FILHO, 2001)

Nos mostra na figura a inadequação para os casos de movimentação das cargas de soja no Brasil. (COSTA, 2002)

Figura 1: Matriz de Transporte para o complexo de soja no Brasil:

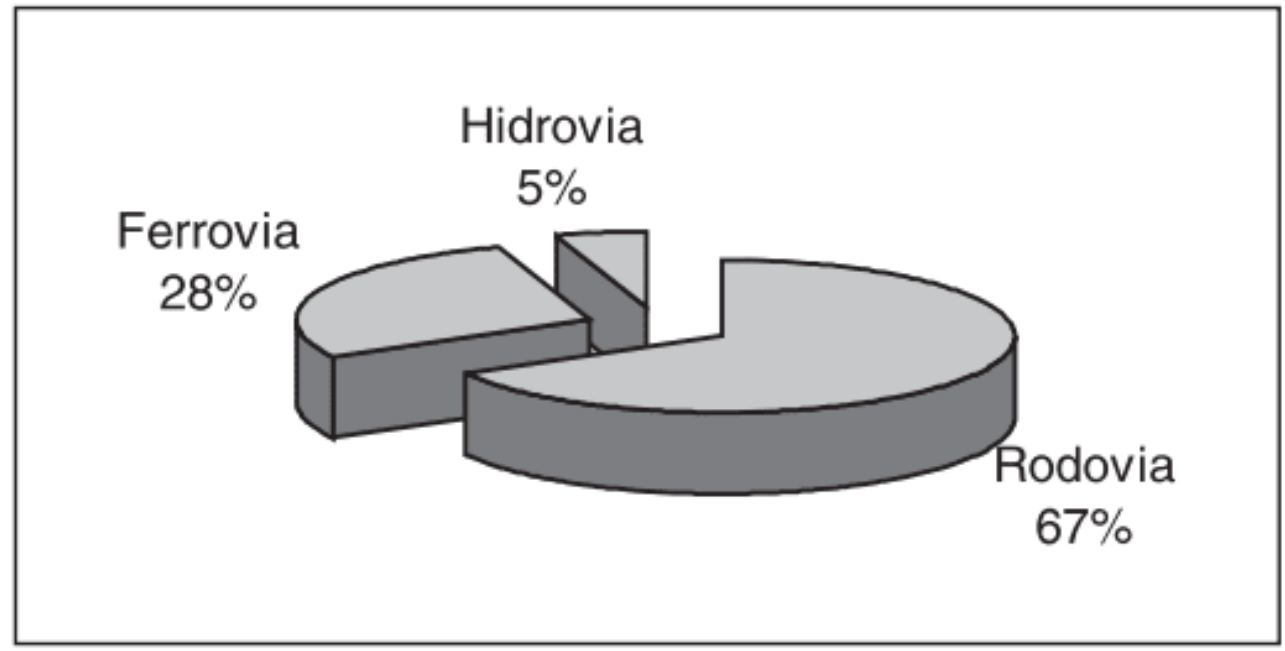

Fonte: Costa et al. (2002).

a safra da soja, que ocorre entre os meses de março e abril, é a que mais desestabiliza o mercado do frete no Brasil. Outro fato também importante a destacar, fato esse negativo, é a lentidão entre a 
propriedade de produção agrícola e a indústria, levando a uma demanda de maior necessidade de manutenção do caminhão, geralmente estas vias são vicinais e não pavimentadas, somando tudo isso, são fatores que também elevam os custos dos fretes. (SOARES 1997).

Figura 2: Logística da distribuição de grãos derivados no Brasil

\section{Logística da distribuição de grãos e derivados no Brasil}

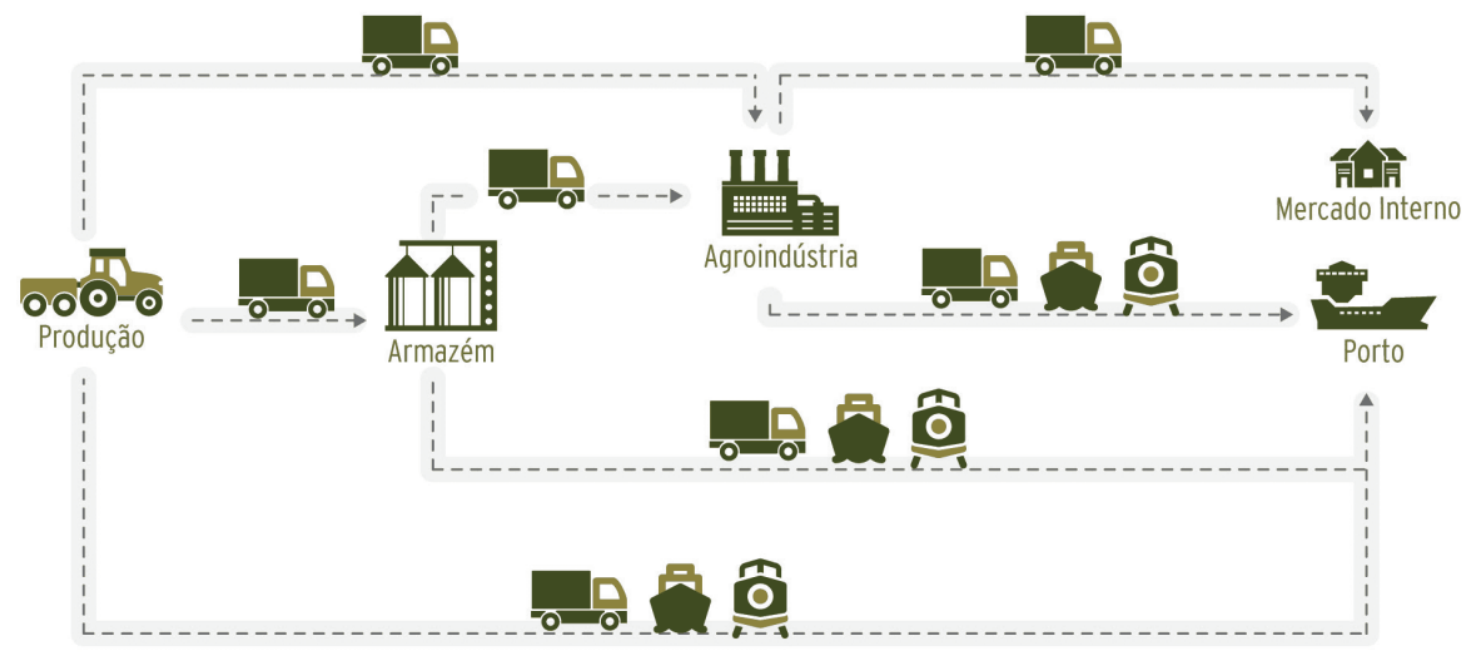

Fonte: Elaboração CNT

Fonte: Elaboração CNT 2014

O balanço do agronegócio realizado pela CONFEDERAÇÃO DA AGRICULTURA E PECUÁRIA DO BRASIL (CNA, 2013 e 2014), nos últimos anos, o Agronegócio destacou-se como fator preponderante para o crescimento econômico do País.

O desempenho poderia ser melhor, se não fossem os custos e os desperdícios gerados pela falta de infraestrutura e logística no Brasil. De acordo com dados da (INTELOG, 2013), para cobrir as despesas com logística são gastos entre 8,5\% e $9,0 \%$ de tudo que é produzido pelo setor.

A infraestrutura ruim também é um dos principais fatores responsáveis, por exemplo, pelo desperdício, conforme figura 2, com a soja. Estima-se que a perda de grãos, da lavoura ao porto, varie entre $6,0 \%$ e $13,0 \%$. 
Figura 3: Custo Logístico

Fonte: *Intelog e **Esalq-USP.

\section{ASPECTOS METODOLÓGICOS}

Os aspectos metodológicos visam descrever os procedimentos utilizados para alcançar os objetivos propostos no trabalho. Iniciou-se pela descrição dos métodos utilizados na operacionalização da pesquisa teórica, apresentando em seguida as técnicas de pesquisa, o universo da pesquisa, e os procedimentos de coleta de dados.

Dentre as diversas formas de o pesquisador fomentar o conhecimento existem diferentes tipos de pesquisa que implicam diretamente em diferentes procedimentos em termos de formulação das questões de pesquisa, métodos e análises.

De acordo com (FLEMING 2008, p. 69, MATTAR 1996), "existem diversas possíveis classificações de tipos de pesquisas, pois o tipo de pesquisa é um conceito complexo que não pode ser descrito de maneira única". 
Esta pesquisa pode ser classificada como um ensaio teórico escrito a partir de uma revisão bibliográfica, sistematização e análise de informações já publicadas referentes ao tema "LOGÍSTICA DO AGRONEGÓCIO".

A natureza da pesquisa, caracteriza-se como básica, objetiva gerar conhecimentos novos, úteis para o avanço da Ciência, sem aplicação prática prevista, envolve verdades e interesses universais. (GERHARDT e SILVEIRA, 2009)

Seu aspecto de abordagem do problema, enquadre-se como qualitativa para a análise do tema e seleção dos artigos e como quantitativa para as demais análises.

Martins e Teóphilo (2007) afirmam que a avaliação qualitativa é caracterizada pela descrição, compreensão e interpretação de fatos e fenômenos. A pesquisa qualitativa descreve a complexidade de determinado problema, analisa a interação de variáveis, compreende e classifica seus processos dinâmicos apresentados.

A abordagem quantitativa, é amplamente utilizada no âmbito dos pesquisadores, (CRESWELL 2007, p. 24), define pesquisa quantitativa como uma "observação cuidadosa e mensuração da realidade objetiva".

Podemos considerar o objetivo deste estudo como exploratório, pois tem como objetivo o aumento do conhecimento em relação ao tema, proporcionando maior familiaridade com o problema a fim de torná-lo explícito. (SILVA e MENEZES, 2005)

Para o desenvolvimento desta pesquisa também foram utilizados dados secundários, os dados utilizados são provenientes do Ministério da Agricultura, Pecuária e Abastecimento e Confederação Nacional do Transporte (CNT).

Segundo Malhotra (2001), a utilização de dados secundários justifica-se em virtude da sua grande abrangência e facilidade de acesso.

Os artigos que serviram de base para esta pesquisa foram selecionados na base de dados do Google "Scholar". Para identificação dos artigos referentes ao tema, foi utilizado as palavras-chave "LOGÍSTICA DO AGRONEGÓCIO". Em um primeiro 
momento foi utilizado o próprio nome tema do artigo "A LOGÍSTICA NAS CADEIAS PRODUTIVAS DO AGRONEGÓCIO", mas a pesquisa não encontrou nada de relevância que pudesse compor alguma amostra.

Em um primeiro momento, não foi estabelecido restrições em questão ao período de busca, desta maneira, 46 (quarenta e seis) artigos que versam sobre o tema da pesquisa e delimitado com as palavras-chave foram encontrados na base de dados citada, porém, após uma profunda análise destes artigos, alguns foram descartados, pois não estavam alinhados perfeitamente com o tema desta pesquisa.

Após esse primeiro filtro, decidiu-se que a análise seria referente às publicações dos anos de 2014 á 2015, portanto uma janela temporal de 1 ano, pois os artigos publicados nestes anos retratam as mais atuais pesquisas referentes ao tema e demonstram os cenários e atores envolvidos atualizados.

$\mathrm{Na}$ apresentação dos dados da pesquisa iremos discutir os resultados da análise de uma amostra dos dados obtidos na base Google Scholar relacionados ao tema deste estudo.

Contudo, posteriormente, os referidos artigos foram analisados e estabelecidos os seguintes critérios: quantidade de artigos por ano; número de autores por artigo; meio de divulgação da pesquisa; tema da pesquisa e qual a contribuição do artigo.

\section{DISCUSSÃO DE QUANTIDADE DE ARTIGOS E ANÁLISE DOS DADOS DA PESQUISA}

Após o filtro temporal e os descartes aplicados a pesquisa, á quantidade de artigos encontrados na base de dados para o tema "LOGÍSTICA DO AGRONEGÓCIO", resultou em 18 (dezoito) artigos, 13 artigos publicados em 2014 e 5 em 2015. A referida distribuição pode ser vista na tabela abaixo. 
Tabela 1: Quantidade de artigos

Ano de Publicação do Artigo

2014

2015

Total
Quantidade de Artigos

13

4

23,52

17

$100 \%$

Fonte: Próprio autor

\subsection{QUANTIDADE DE AUTORES POR ARTIGO E MEIO DE PUBLICAÇÃO DA PESQUISA}

Avaliando e quantificando o número de autores por artigo pesquisado, ou seja, artigos publicados, constata-se que uma substancial parte dos trabalhos são conglomerados por 1 e 3 autores, que juntos correspondem a 76,46\% do total de artigos. Percebe-se claramente que os trabalhos com 1 autor estão em mais evidência representando $52,94 \%$ dos trabalhos publicados.

Artigos escritos por 2 autores correspondem a uma amostra de tamanho de número 3 o que equivale a $17,64 \%$ da análise amostral, os de 4 autores são ainda menos significativos, correspondem a uma amostra de tamanho que representa 5,88\% de todo o conjunto de dados amostrais. 
Tabela 2: Quantidade de autores por artigo

\begin{tabular}{ccccc} 
Número de autores por artigo & 2014 & 2015 & Total & $\%$ \\
1 & 7 & 2 & 9 & $52,94 \%$ \\
\hline 2 & 3 & 0 & 3 & $17,64 \%$ \\
\hline & 2 & 2 & 4 & $23,52 \%$ \\
5 & 1 & 0 & 0 & $5,88 \%$ \\
\hline
\end{tabular}

Fonte: Próprio autor

Considerando a análise executada dos dados, conclui-se que, grande parte dos artigos publicitados dentro da pesquisa, resulta-se de colaboração entre os pesquisadores investigadores, e que esta colaboração se limita entre 1 a no máximo 3 autores, sendo observado na tabela de análise de quantidade de autores por artigo.

Se observarmos na tabela abaixo podemos verificar que a Revista AGROANALYSISFGV, apresentar o maior fator de impacto, pois aparece com 7 publicações no sistema pesquisado por este estudo, sendo 4 publicações em 2014 e 3 publicações em 2015, até julho. Referente as demais publicações, as mesmas são publicações únicas não possuindo demais quantificações de busca. 
Tabela 3: Quantidade de Artigos e Revistas

REVISTA

QUANT. ARTIGOS

156 CONTEXTUS Revista Contemporânea de Economia e Gestão. Vol 13 - No

156 CONTEXTU
$1-$ jan/abr 2015

AGROANALYSIS - FGV

Blucher Proceedings / In Anais do XVII Simpósio de Pesquisa Operacional e

Logística da Marinha - SPOLM 2014 [=Blucher Engineering Proceedings, n.1,

v.1]. São Paulo: Blucher, 2014

Caderno de Ciências Humanas e Sociais Aplicadas $\mathrm{n}^{\circ} 4$

COVIBRA - ADMINISTRAC̣ÄO

Enciclopédia Bioesfera: Centro científico conhecer

ENGEMA: Encontro Internacional sobre Gestão Empresarial e Meio Ambiente

ESALQ-LOG - Grupo de Pesquisa e Extensão em Logística Agroindustrial

Departamento de Economia, Administração e Sociologia Escola Superior de Agricultura "Luiz de Queiroz" (ESALQ/USP)

Seminário: Ciências Agrárias / Periódicos Científicos da UEL

Unioeste: Faz ciência v16

Vl: Congreso Iberoamericano de Estudios Territoriales y Ambientales

Fonte: Próprio autor

Dentro do tema de limitação de pesquisa foram encontrados 17 artigos com várias abordagens referentes á Logística do Agronegócio e Logística nas Cadeias Produtivas do Agronegócio. A classificação do estudo está na tabela abaixo. 


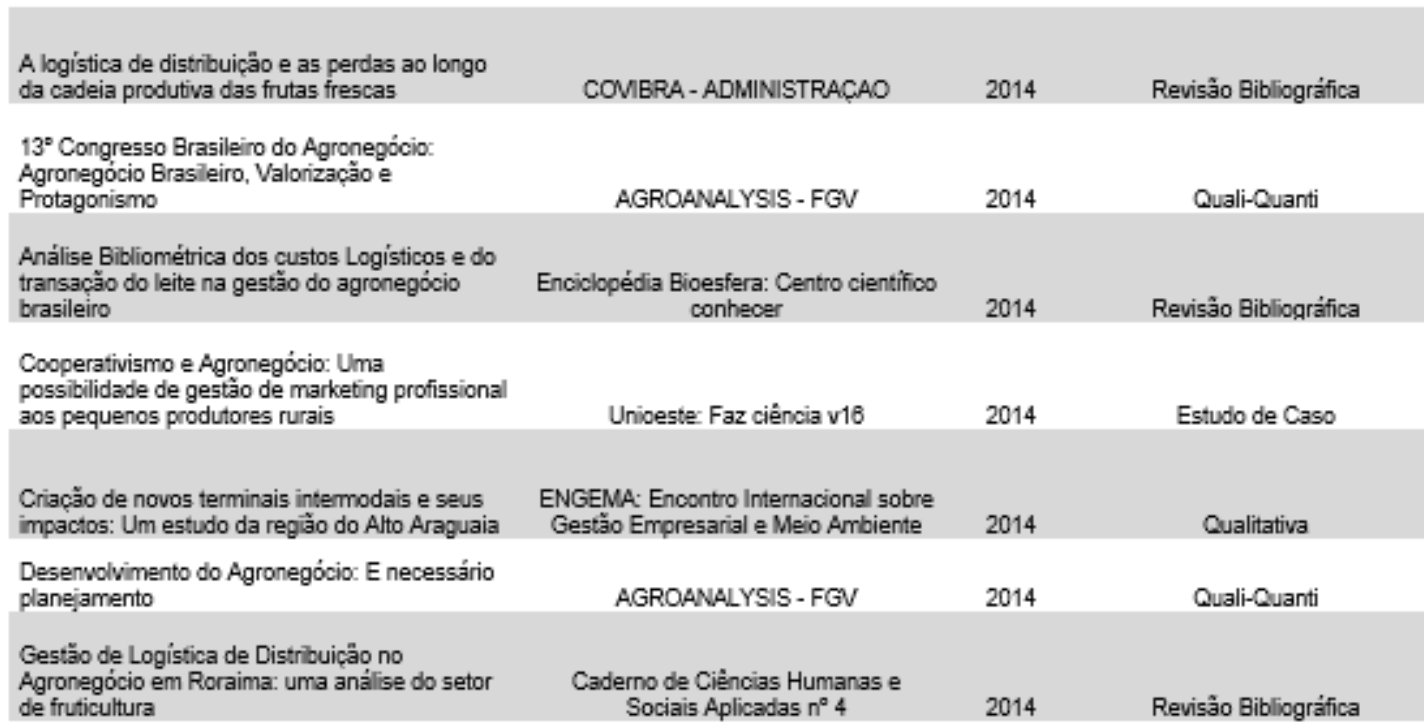

\begin{tabular}{|c|c|c|c|}
\hline $\begin{array}{l}\text { Identificação e Elaboraçăo de Variáveis } \\
\text { Estatísticas Através de Técnicas Multivariadas no } \\
\text { Estudo da Produç̃o de Grăos e Fibras, na } \\
\text { Reqiảo Administrativa de Presidente Prudente-SP }\end{array}$ & $\begin{array}{c}\text { Semina: Ciências Agránias / Periódicos } \\
\text { Científicos da UEL }\end{array}$ & 2014 & $\begin{array}{l}\text { Misto com aplicaçăo de modelos } \\
\text { matemáticos }\end{array}$ \\
\hline $\begin{array}{l}\text { Implicaçöes do sistema de segregaçäo do milho } \\
\text { na Logística de Transporte Brasileira: Aplicaçäo } \\
\text { de um problema de complementariedade mista }\end{array}$ & $\begin{array}{c}\text { Blucher Proceedings / In Anais do XVII } \\
\text { Simpósio de Pesquisa Operacional e } \\
\text { Logística da Marinha - SPOLM } 2014 \\
\text { [=Blucher Engineering Proceedings, n.1, } \\
\text { v.1]. Săo Paulo: Blucher, 2014. }\end{array}$ & 2014 & Modelo Matemático \\
\hline $\begin{array}{l}\text { Infraestrutura Logística do Brasil:Uma análise } \\
\text { comparativa entre os anos de } 2011 \text { e } 2014 \text { e } \\
\text { possiveis impactos no desenvolvimento do } \\
\text { agronegócio }\end{array}$ & $\begin{array}{c}\text { ESALQ-LOG - Grupo de Pesquisa e } \\
\text { Extensảo em Logística Agroindustrial } \\
\text { Departamento de Economia, } \\
\text { Administracăo e Sociolopia Escola } \\
\text { Superior de Agricultura 'Luiz de } \\
\text { Queiroz' (ESALQUSP) }\end{array}$ & 2014 & Revisão Bibliográfica \\
\hline $\begin{array}{l}\text { Governança da produçăo de frutas no Nordeste } \\
\text { Brasileiro: O papel dos Supermercados }\end{array}$ & $\begin{array}{l}\text { V: Congreso Iberoamericano de } \\
\text { Estudios Tenitoriales y Ambientales }\end{array}$ & 2014 & Modelo Conceitual \\
\hline Mais inovaçăo e dinamismo & AGROANALYSIS - FGV & 2014 & Modelo Conceitual \\
\hline Um chamamento para o agronegócio & AGROANALYSIS - FGV & 2014 & Modelo Conceitual \\
\hline 2015, uma aventura complexa & AGROANALYSIS - FGV & 2015 & Modelo Conceitual \\
\hline $\begin{array}{l}\text { Logística: Impacto na receita dos produtores de } \\
\text { soja }\end{array}$ & AGROANALYSIS - FGV & 2015 & Quali-Quanti \\
\hline $\begin{array}{l}\text { O Agronegócio é o seguinte: Balanço da taxa de } \\
\text { inflacão }\end{array}$ & AGROANALYSIS - FGV & 2015 & Quantitativo \\
\hline $\begin{array}{l}\text { Uma lógica contigencial de sistemas de custos na } \\
\text { atividade apricola }\end{array}$ & $\begin{array}{c}156 \text { CONTEXTUS Revista } \\
\text { Contemporânea de Economia e Gestâo. } \\
\text { Vol } 13-N^{2} 1-\text { ian/abr } 2015\end{array}$ & 2015 & Qualitativa \\
\hline
\end{tabular}

Fonte: Próprio autor

Observou-se que a metodologia empregada nos artigos durante a efetivação deste estudo foi que em $29,41 \%$ dos artigos publicitados a metodologia foi o estudo de caso. 
Outra metodologia também que cabe ressaltar foi a de modelo conceitual e qualiquanti ambas com $17,64 \%$.

Dentro da janela temporal de delimitação da pesquisa para este estudo, nota-se que em 2014 a metodologia mais utilizada foi a de Revisão Bibliográfica correspondendo a $23,53 \%$ dos artigos.

Em 2015 até julho observou-se que nenhum artigo tinha apresentado o aspecto metodológico de Revisão Bibliográfica. A referida distribuição encontra-se na tabela 4.

\begin{tabular}{lcc|}
\multicolumn{1}{c}{ Metodologia } & $\begin{array}{c}\text { Quantidade de } \\
\text { Artigos }\end{array}$ & $\%$ \\
\hline Estudo de Caso & 1 & $5,88 \%$ \\
\hline $\begin{array}{l}\text { Misto com aplicação de modelos } \\
\text { matemáticos }\end{array}$ & 1 & $5,88 \%$ \\
\hline Modelo Conceitual & 3 & $17,64 \%$ \\
\hline Modelo Matemático & 1 & $5,88 \%$ \\
\hline Quali-Quanti & 3 & $17,64 \%$ \\
Qualitativa & 2 & $11,76 \%$ \\
\hline Quantitativo & 1 & $5,88 \%$ \\
\hline Revisão Bibliográfica & 5 & $29,41 \%$
\end{tabular}

Fonte: Autor.

\section{CONSIDERAÇÕES FINAIS}

O estudo executado teve como objetivo primordial explorar e quantificar a produção científica em relação às principais propriedades das pesquisas relacionadas á logística na cadeia produtiva do agronegócio. Este estudo contribui para a percepção e mapeamento dos principais temas abordados dentro da área e as principais metodologias empregadas.

Podemos afirmas que a pesquisa atingiu seu objetivo, pois foi possível identificar, quantificar e qualificar artigos referentes ao tema e determinar as tendências de pesquisas na área da logística na cadeia produtiva do agronegócio. 
Diante das análises feitas neste estudo observou-se que os autores que publicaram artigos sobre o tema analisado, limitam-se, em poucas parcerias, observa-se que a maior parte das pesquisas publicadas é composta por dois a três autores.

Em referência aos temas abordados dentro da área da logística na cadeia produtiva do agronegócio, nota-se que os artigos avaliados durante a realização deste estudo enfocam temas como logística e distribuição da cadeia produtiva, custos logísticos, criação de novos terminais intermodais e desenvolvimento do agronegócio.

Por fim, o tema tratado neste artigo é de interesse dos segmentos de empresas públicas e privadas do setor do agronegócio e de logística, sendo um importante instrumento para a sensibilização sobre o atual cenário que se encontra a logística do agronegócio brasileiro e suas principais necessidades pulsantes e emergenciais.

\section{REFERÊNCIAS}

ABRALOG. <http://www.abralog.org.br/website/home/>. Acesso em: 13 jul.2015.

ALVARENGA, Antônio C. NOVAES. Antonio G. N. Logística Aplicada: suprimento e distribuição física. 3ª edição. São Paulo. Ed.Edgar Blucher Itda. 2000.

ANDRADE, M.M. Como Preparar Trabalhos para Cursos de Pós-Graduação: noções práticas. 5. ed. São Paulo: Editora Atlas 2002.

BALLOU, Ronald H. Gerenciamento da Cadeia de Suprimentos/Logística Empresarial. 5a. ed. Porto Alegre: Bookman, 2006. ,p.26

BALLOU, Ronald H. Logística Empresarial: transportes, administração de materiais e distribuição física. 1르 ed. São Paulo: Atlas, 1993.

BATALHA, M. O . Gestão Agrocinustrial. São Paulo: Atlas, 2001

BATALHA, Mário O.(coord.). Gestão Agroindustrial: GEPAI: Grupo de Estudos e Pesquisas Agroindustriais. Vol. 1. 2. ed. São Paulo: Atlas, 2001. 
BAYLISS, B.Transport policy and planning: anintegrated analytical approach.Washington: The World Bank, 1996.

BEILOCK, R. et al.Road conditions, border crossing and freight rates in Europe and Western Asia. Transportation Quarterly, v. 50, n. 1, p. 79-90, Winter 1996.

BLOG DO PLANALTO. <http://blog.planalto.gov.br/assunto/ministerio-da-agricultura/ >. Acesso em: 13 jul.2015.

CAIXETA-FILHO, João V. MARTINS, Ricardo S (Org). Gestão logística do transporte de cargas. São Paulo. Ed. Atlas. 2001.

CANAL DO

PRODUTOR.

ttp://www.canaldoprodutor.com.br/http://www.eumed.net/cursecon/ecolat/br/>.

Acesso em: 13 jul.2015.

CARLOS Lourenço y Barbosa de Lima: "Evolução do agronegócio brasileiro, desafios e perspectivas"en Observatorio de la Economía Latinoamericana, Número 118, 2009. Texto completo en <http://www.eumed.net/cursecon/ecolat/br/>. Acesso em: 13 jul.2015.

CARVALHO, José Meixa Crespo de - Logística. 3aㅗ ed. Lisboa: Edições Silabo, 2002. ISBN 9789726182795

CARVALHO, José Crespo de - Logística, Supply Chain \& Network Management. Lisboa. Ad litteram, 2003.

CHRISTOPHER, Martin. Logistics and Supply Chain Management. 4. ed. São Paulo. Cengage Learning. 2012.

CHOPRA, Sunil, Gestão da cadeia de suprimentos, estratégias, planejamento e operações / Sunil Chopra, Peter Meindl; tradução Daniel Vieira; Revisãp técnica Marilson Alves Gonçalves. 4 ed. São Paulo: Pearson Prentice Hall, 2011.

COASE, R. H. The nature of the Firm. Econômica, v. 04, n.16, p. 386-405, nov./1937. 
COLLIS, J.; HUSSEY, R. Pesquisa em Administração: Um guia prático para alunos de graduação e pós graduação. 2. ed. São Paulo: Artmed, 2005.

CONFEDERAÇÃO DA AGRICULTURA E PECUÁRIA DO BRASIL CNA. Disponível em: < http://www.cna.org.br/site/agencia/>. Acesso em: 13 jul.2015.

CONFEDERAÇÃO DA AGRICULTURA E PECUÁRIA DO BRASIL CNA. Disponível em: < http://www.cna.org.br/site/pesquisa/>. Acesso em: 15 jul.2015.

. Conceitos gerais, evolução e apresentação do sistema agroindustrial. In:

ZYLBERSZTAJN, Decio; NEVES, Marcos F. (Org.). Economia e gestão dos negócios agroalimentares. 1. ed. São Paulo: Pioneira Thomson, 2005. p. 01-21.

CRESWELL, J. W. Projeto de Pesquisa. Porto Alegre: Artmed, 2010.

CRUVINE, Paulo E.; MARTIN NETO, Ladislau. Subsídios para o Desenvolvimento do Agronegócio Brasileiro: o Programa Automação Agropecuária, Visão e Estratégias. Embrapa: Comunicado Técnico, n. 32, p. 1 - 4, set. 1999.

CONTI, Maria Laura. Esame e confronto di differenti soluzioni al problema del transporto merci in âmbito urbano. Università di Parma: Ottobre, 2004.

DAVIS, J.H.; GOLDBERG, R.A. The genesis and evolution of agribusiness. In: DAVIS, J.H.;GOLDBERG, R.A. A concept of Agribusiness. Harvard University. Pp.4-7

DAVIS, J.H.; GOLDBERG, R.A. The genesis and evolution of agribusiness. In: DAVIS, J.H.; GOLDBERG, R.A. A concept of Agribusiness. Harvard University. Pp.7-23

DIAS, João Carlos Quaresma - Logística global e macrologística. Lisboa: Edições Silabo, 2005. ISBN 9789726183693

. Economia das organizações. In: ZYLBERSZTAJN, Decio; NEVES, Marcos F. (Org.). Economia e gestão dos negócios agroalimentares. 1. ed. São Paulo: Pioneira Thomson, 2005. p. 23-38. 
FERREIRA, Aurélio Buarque De Holanda. Novo Dicionário Aurélio da Língua Portuguesa. $2^{\mathrm{a}}$ ed. Rio de Janeiro: Nova Fronteira, 1986.

FLEURY, Paulo F. WANKE, Peter. FIGUEIREDO, Kleber F. (Org). Logística Empresarial: a perspectiva brasileira. São Paulo. Ed. Atlas. 2000.

FLEMING, M. C. N. C. O papel da esperança na compra de crédito pessoa em consumidores de baixa renda, Dissertação (Mestrado em Administração). Faculdades Ibmec, Rio de Janeiro, 2008.

GOLDBERG,R.A. Agribusiness Coordination: A Systems approach to the wheat, soybean and florida orange economies. Harvard University, 1968.

HANDFIELD, Robert B. STRAUBE, Frank PFOHL, Hans WIELAND, Andreas. Trends and Strategies in Logistics and Supply Chain Management: Embracing Global Logistics Complexity to Drive Market Advantage. BVL. 2013 KUNRATH, Rodrigo Diedrich - Logística Empresarial.

MALHOTRA, N. Pesquisa de marketing: uma orientação aplicada. 3ª edição. Porto Alegre: Bookman, 2001.

MARTINS, G. A.; THEÓPHILO, C. R. Metodologia da investigação científica para ciências sociais aplicadas. São Paulo: Atlas, 2007.

Métodos de pesquisa / [organizado por] Tatiana Engel Gerhardt e Denise Tolfo Silveira ; coordenado pela Universidade Aberta do Brasil - UAB/UFRGS e pelo Curso de Graduação Tecnológica - Planejamento e Gestão para o Desenvolvimento Rural da SEAD/UFRGS. - Porto Alegre: Editora da UFRGS, 2009. Disponível em: $<$ <ttp://www.ufrgs.br/cursopgdr/downloadsSerie/derad005.pdf >. Acesso em julho de 2015.

NOVAES, G. A. Logística e gerenciamento da cadeia de distribuição. Rio de Janeiro. Ed. Campus. 2000. 
OLIVEIRA, F. Além da transição, aquém da imaginação. Novos Estudos CEBRAP, São Paulo, n.12, p.2-15, jun. 1985.

POZO, Hamilton, Administração de Recursos Materiais e Patrimoniais: uma abordagem logística / Hamilton Pozo. - 6.ed. São Paulo : Atlas 2010. p. 133.

PORTAL NTC. Disponível em: <http://www.portalntc.org.br/>. Acesso em julho de 2015.

Principais determinantes de preço do frete rodoviário para o transporte de soja em grãos em diferentes Estados brasileiros: uma análise econométrica. 2001. 83 f. Dissertação (Mestrado em Economia Aplicada) - Universidade de São Paulo - USP, São Paulo.

REDETEC.

$<$ http://redeetec.mec.gov.br/images/stories/pdf/eixo_rec_naturais/aquicultura/181012 _emp_agro_iv.pdf>. Acesso em julho de 2015.

RENAI. A Rede Nacional de Informações sobre o Investimento. O Setor deAgronegócio no Brasil: Histórico e Evolução do Agronegócio Brasileiro.Disponível em: http://investimentos.desenvolvimento.gov.br/intern>. Acesso em: 29 jan.2009.

RODRIGUES, Roberto. O céu é o limite para o agronegócio brasileiro. Conjuntura Econômica, Rio de Janeiro, V.60, n.11, p.1415, Nov.2006.

STEFANELO, Eugênio L. Agronegócio brasileiro: propostas e tendências. Revista FAE Business. n 3, set. 2002. p.10

TÁNCZOS, K.; BOKOR, Z. Elaborating a city-logistic conception for the case of Budapest. Transportation and Telecommunication in the 3rd Millenium, 10th Anniversary of the Foundation of the Faculty Transportation Sciences.

TRIVIÑOS, A.N.S. Introdução à pesquisa em ciências sociais - A pesquisa qualitativa em educação. São Paulo: Atlas, 2008. 
VERGARA, S. C. Métodos de Pesquisa em Administração. 2. ed. São Paulo: Atlas, 2006.

ZYLBERSZTAJN, D.; NEVES, M. F.; et al. Economia e Gestão dos Negócios Agroalimentares. São Paulo: Pioneira, 2000. p.1-21.

Enviado: Abril, 2019.

Aprovado: Agosto, 2019. 